\title{
Nietzsche: A Religião da Compaixão e o Espelho do Ocidente
} Fernando R. de Moraes Barros (Bolsista CNPq - DF/USP/SP) Orientadora: Scarlett Marton

Trazer à plena luz a discussão de Nietzsche acerca da religião da compaixão e sua influência sob o processo gregário ocidental demanda, sobretudo, uma certa acuidade. Aqui o pano de fundo não é constituído pela abordagem "pro-vocativa" repetida ad nauseam no cenário iconoclasta, mas, de maneira incomparavelmente a mais fecunda, pela abordagem psico-fisiológica que falar ao abismo não preenchível dos labirintos conceituais a linguagem da vida mesma.

Pretender a interpretação religiosa da existência baseada na caritas como matéria de análise e observar seus "vaivéns" dentro do próprio levante ocidental significa, em linhas gerais, perscrutar o âmbito civilizatório sem perder de vista o que dormita nos seus moldes, nas suas árvores metafísicas. Tal exigência leva, infalivelmente, ao questionamento do "modelo" valorativo cristão-ocidental.

Entrementes, a análise a partir da obra $O$ Anticristo é determinante para o objetivo geral de nossa investigação, donde, já no início da primeira seção do texto a voz do filósofo enuncia: Encaremos nós mesmos de frente. Nós somos hiperbóreos, sabemos muito bem o quão distante vivemos."

Ora, tal ponto de partida não é fortuito e cumpre, portanto, iniciar o exercício de reflexão em sintonia com o olhar "distante" trazido pelo texto.

Olhar que põe a nu o homem moderno, que mostra sua incapacidade decisória latente e que traz à tona seu suspiro: "Eu não sei o que fazer; eu sou tudo isso que não sabe o que fazer." ${ }^{\text {"2 }}$ Assim, a posição albergada pelo filósofo toma um certo distanciamento em relação ao âmbito no qual o homem moderno orbita e deve ser considerada como parte de um propósito que vai além de seu próprio tempo.

É preciso sublinhar que, sobretudo em O Anticristo, o patamar reflexivo no qual as questões são batizadas não remete o leitor a uma cronologia determinada, ou seja, é a própria humanidade presente durante dois milênios no terreno cristão-ocidental que irá ser descortinada, incluindo a soma de seus construtos teóricos e a cumulação das ambivalências inerentes ao processo de sua formação.

Tal é o "complexo" que forma o objeto no qual Nietzsce irá desenvolver sua análise. Acerca desta riqueza e multiplicidade Patrick Wotling comenta: "É preciso sublinhar o alcance do campo coberto por essa noção englobante, congregante, totalizante mesma, na qual as morais, as religiões, os sistemas filosóficos, os códigos jurídicos, as correntes políticas ou a arte são da mesma maneira elementos particulares." ${ }^{3}$ De sorte que a banal cronologia das ocorrências civilizatórias é abandonada para que a reflexão sobre esses elementos convergentes ganhe independência e amplitude.

A partir desse horizonte temático, Nietzsche elabora a discussão acerca da religião da compaixão. Sem a ambição de tomar parte no jogo escuso promovido pelo "império das provas e das refutações" o filósofo alemão parece, por assim dizer, roçar a caritas com a ponta dos dedos e faz surgir, como conseqüência de tal desa- 
fio, o demarcamento de toda uma escala de valores inscritos na própria urbe, no rebanho.

Atrás da cortina que tapa o ardiloso e secreto processo da compaixão, é possível detectar a presença de um mecanismo engendrador de descontentamento decisivo, isto é, ao transformar o sofrimento alheio no próprio, a compaixão confere à vida mesma um caráter de resignação e forja um universo ilusório de impulsos solidamente ancorado na máxima omnes, quantum potes, iuva.

Sobre a base de tal máxima se institui e consolida uma estrutura relacional que é pressuposto de toda e qualquer forma de livre-arbítrio, ou seja, agir de acordo com a consciência de tal obrigação implica, inevitavelmente, numa faculdade na qual a ação possa ser representada pela capacidade interna de determinação da própria vontade. Com isto, o dever contraído que repousa sob a fachada de tal máxima impele escrupulosamente o agir humano à compaixão.

Acostumado ao jogo escuso da sagacidade teológica, Nietzsche desmascara a idéia astuta de uma vontade livre, isto é, de uma espécie de dom natural concedido ao homem para que tivesse a possibilidade de escolher. Neste sentido escreve: "Hoje nós não temos mais qualquer simpatia pelo conceito de "vontade livre": nós sabemos muito bem o que ele realmente é - o mais poluído de todos os artifícios dos teólogos, planejado para tornar a humanidade "responsável" no sentido deles, isto é, dependente deles."

Entrementes, a compaixão apoiada na doutrina do livre-arbítrio deu início ao trabalho de modelagem que, rudimentarmente, constituiu o princípio canonizante e norteador da atividade humana, enfim, o próprio fulcro de processo gregário. Assim, de maneira hegemônica, o labor teológico conduziu o itinerário humano através do cândido manto da caritas, elemento de um arsenal conceitual que parece estar acima de qualquer exame ou questionamento.

Ora, forjada a partir da vontade livre, a compaixão sustenta que cabe ao indivíduo fazer suas escolhas, submeter-se a ela ou não, contudo, é obrigado a responder pelas conseqüências de suas ações. Doravante, as expiações (Bussen) exigidas pela consciência de culpa (Schuldbewusstsein) passam a desempenhar o prodigioso papel de bússula orientadora em direção ao bem da coletividade.

Nietzsche, de seu lado, não hesita ao descrever esse fenômeno prenhe de pusilanimidade: "Doloroso, estremecedor é o espetáculo que surgiu em minha frente: abri a cortina que tapava a corrupção do homem." Aqui, portanto, a corrupção é analisada a partir de uma noção que abarca as próprias bases que o Ocidente lançou mão na tentativa de espelhar (widerspiegelt) o mundo, isto é, o leitmotif tende a englobar, em certo motivo, o "problema da civilização"

À guisa de compreensão, é preciso sublinhar o aspecto inovador da reflexão nietzschiana acerca de tal problema. Aqui, cultura e civilização não constituem uma oposição radicalmente distintiva, a primeira não dá conta apenas do domínio da vida "intelectual" enquanto a segunda, por sua vez, trata das condições materiais e práticas que caracterizam a vida gregária. Nietzsche, ao desenvolver seu pensamento, anula tal distinção e recusa a concepção dualística na qual teoria e prática implicam uma oposição.

No entender do filósofo, é preciso fundir esses horizontes e dar vazão aos elementos significativos da vida mesma, de sorte que ...essas pequenas coisas - alimentação, lugar, clima, distração, toda a casuística do egoísmo - são inconcebivelmente mais 
importantes do que tudo o que até agora tomou-se como importante. Nisto exatamente é preciso começar a reaprender." ${ }^{\prime 6}$ Contudo, esses aspectos foram agenciados pelo ideário religioso como sendo algo de segunda ordem, isto é, como "coisa de ninguém", como res nullius.

De maneira que o "complexo" civilizatório, tal como Nietzsche o descreve, tomou como suprema aspiração e estimativa de valor o próprio desdenho em relação aos aspectos por fórmulas e coordenadas fictícias construídas a torto e a direito.

Vítrea, a interpretação religiosa da existência baseada na caritas, deixa entrever uma utilidade definida e opera uma função prática em relação aos anseios e limitações do levante ocidental. Tal interpretação opera, em linhas gerais, dois movimentos basilares, ou seja, é possível vislumbrar o interesse do poderio ascético que necessita assegurar seu papel regulativo e o interesse dos esgotados (Erschöpften) em garantir uma forma de nutriente sentimental (empfindsam).

Nietzsche, de seu lado, lança nova luz ao questionamento e aponta para um alerta contra tal interpretação, contra esa "fábrica de ilusões" que ajudou a construir as bases da prisão óptica na qual o homem se achou trancafiado ao crer na unidade espiritualmaterial de sua existência. Empenhada na montagem de representações exatas, em espelhar um mundo uno e igual a si mesmo, a escrupulosa "visão de mundo" cristãocidental tende a retratar as "virtudes", "os sentimentos superiores", enfim, a própria "divindade" do rebanho.

Daí a aura de superioridade de tais "virtudes", ou seja, pela elaboração identificatória o ocidente elegeu para si mesmo valores incondicionais de exclusiva relevância. Eis porque, no entender de Nietzsche, os valores supremos presentes no seleto rol das estimativas ocidentais, isto é, o Bem, o Verdadeiro, o Justo e o Belo fazem parte do resultado de uma escolha classificatória.

O emprego desse espelhamento foi de tal maneira consolidado que sua função canonizante dentro do processo gregário adquiriu um estatuto da ordem do absoluto, isto é, em tal terreno tudo gira em torno da imagem unívoca do espelho instaurado pela metáfisica cristalizada como esquema normativo, ou, em outras palavras, pelo programa camaleônico do ascetismo. Espelhamento que é, no limite, a própria bússula norteadora em direção ao "divino", a importante estrela polar dos que navegam pelas águas da metafísica e que se fiam na fixidez dos valores.

Assim, a caritas também reivindicou seu lugar no "ideal" do espelhamento que, por sua vez, cumpriu a tarefa incondicionada de zelar pela identidade entre um sentimento e o todo existente. De tal forma que foi sob a perspectiva do a parte ad totum que a caritas brotou e cresceu enquanto critério avaliador do mundo espelhante cristão-ocidental.

Contudo, por mais que tente assegurar a identidade entre suas representações e 0 mundo, por mais "oceânico" que seu alcance pretenda ser, o espelho valorativo do Ocidente, tal como todo espelho, possui um limite e não pode efigiar tudo. Portanto, está longe de refletir aquilo que permanece "escondido" por detrás de tais "virtudes" e "ideais da humanidade"

O próprio mal-estar (Schlecht-Befinden) que trespassa o processo gregário surge como sintoma de décadence, pois, as cobranças instintivas presentes sob o regaço de qualquer civilização, de qualquer "tribo acidental", não são passíveis de controle e estão sempre dispostas a cercear os sentimentos de exatidão e de segurança tão caros ao homem do rebanho. 

$-\longrightarrow-$ 


\section{BIBLIOGRAFA}

Obras de Nietzsche

O Anticristo. Tradução de Andrés Sánchez Pascual. Madri, Alianza Editorial, 1996.

Ecce Homo. Tradução de Paulo César de Souza. São Paulo, Cia. das Letras, 1995.

Obras incompletas. Coleção "Os Pensadores". Tradução de Rubens Rodrigues Torres

Filho. São Paulo, Abril Cultural.

Obras de Comentadores

Assoun, Paul-Laurent. Freud \& Nietzsche: Semelhanças e Dessemelhanças. Tradução de Maria Lúcia Pereira. São Paulo, Brasiliense, 1989.

Giacoia, Oswaldo. O Grande Experimento: Sobre a Oposição entre Eticidade (Sittlichkeit)

e Autonomia em Nietzsche. Em: Trans/Form/Ação, São Paulo, 12: 97-132, 1989.

Wotling, Patrick. Nietzsche et le Problème de la Civilisation. Paris, PUF, 1995.

\section{NOTAS}

1. O Anticristo \#1.

2. O Anticristo \#1.

3. Wotling, Patrick. Nietzsche et le Problème de la Civilization. Paris, Presses Universitaires de France, 1995. P. 14.

4. Crepúsculo dos Ídolos, "Os Quatro Grandes Erros" \#7.

5. O Anticristo \#6.

6. Ecce Homo, "Por que sou tão Inteligente" \#10.

7 O Anticristo \#15.

8. O Anticristo \#11. 